\title{
A Comparative Study of Sino-US Business Negotiation Based on Hofstede's Value Dimensions
}

\author{
Xiao-Ying Yao \\ School of Foreign Languages, Henan Institute of Engineering, Zhengzhou, China 451191 \\ Email: yaoxiaoying231@163.com
}

\begin{abstract}
The purpose of this study is to express how culture influences negotiation and misunderstandings are made due to different cultural values between Chinese and American business negotiations; to show further research of the cultural differences during business negotiation depending on comparative analysis and case study; thus give some tentative advices for future scholars to research the Sino-US business negotiation; come up with some reasonable proposals in order to decrease avoidable miscommunications or failures in intercultural business negotiations, following on these, people who engage negotiation can scheme the process and adopt proper strategies for the sake of achieving anticipative agreements and accomplishing business cooperation.
\end{abstract}

Keywords-Comparative study; Intercultural business negotiation; Culture dimensions

\section{INTRODUCTION}

As we know, effective negotiations not only need to acquire skillful communicative abilities, but also understand the cultural backgrounds of the negotiation mutually (Kremenyuk, 2002). Culture plays a major role in international negotiation practice. Culture not only influences people's thought, communication, and behavior profoundly, but also affects the patterns of transaction and negotiation during the business activity. Cultural differences certainly affect the strategies and behaviors of negotiation, which may hinder the negotiating process and result in negotiation breakdown or failures. A variety of cultures in the world make it impossible for any experienced or skilled negotiator to master completely the situations that may be encountered. People should prepare to cope with any unexpected matters during the business processes. So it is important to study the various cultural issues to avoid the failure of the intercultural business negotiation. China and America are two typical countries of cultural differences, a comparative study of Sino-US business negotiation is the requirement of social developing and it is of realistic significance, which is helpful to negotiation. There are some incompatible appearances between American and Chinese approaches. Americans regard Chinese negotiators as ineffective, roundabout, and even trickish, while the Chinese regard American negotiators as radical, selfish, and aggressive. These differences root in their cultural backgrounds and may result in misunderstanding of negotiation. It is complicated to handle the situations of business negotiation. Hence, the better understanding of the mutually cultural differences can avoid conflicts between two parties and then produce harmonious business relationships in the Sino-US business negotiation.

\section{INTERCULTURAL NEGOTIATION AND HOFSTEDE'S VALUE DIMENSIONS}

With the economic globalization, negotiators have been facing more complex environments, in order to possess opportunities and achieve success in the global marketplace, they need to not only make business deals between different countries and regions, but also handle the business relationships availably from beginning to end. As a global negotiator, it is important to have the skills to deal comprehensively with the entire transaction from the first hand shake with a potential foreign partner to the final liquidation of intercultural negotiation activities that have served their purpose and increased one's business opportunities (Salacuse, 2003). The intercultural negotiators should respect several rules as follows: nature of the control and decision making structure on either side; reasons for trusting or distrusting the behavior of the other side; tolerance for ambiguity during the negotiation process; and emotional needs of negotiators such as ego enhancement or ego effacement (Hofstede, 2001, p.435). Kremenyuk also notes that any intercultural negotiation comprises a range of interrelated factors that must be examined together to be properly understood, and these are: substance of what is being negotiated and the outcome; the diachronic and synchronic environments in which the negotiation take place; taking into account other negotiations that have already taken place or are taking place simultaneously; the process of negotiation, its sequential phase, and the related organizational and procedural matters, including the interrelated negotiations that happen in parallel with the formal process; and the role of the negotiation.

Negotiations are impacted by culture. The strategic behavior, the social motives and the confrontational style of negotiation are affected by culture which generates opportunities to create profits through trade-offs. The final agreements of the negotiation may be prevented by the cultural difference between the negotiators. Intercultural negotiations are more complex and changeable than 
mono-cultural because of cultural elements, settings, languages, ideologies, and customs (Woo, 2009). As everyone knows, in mono cultural negotiations, both parties face the same social, political, and economic environments, which may be particularly stable in some circumstances. In intercultural negotiations, interests, strategies and outcomes of the negotiation are directly affected by the different social, political, and economic environments, then the negotiating settings are more complex(Taylor, C,2006). Due to the obstacle of cultural aspects, many negotiators may miss understanding of the counterparts' backgrounds, and consequently fail in reaching the agreement. Therefore, it is beneficial to understand the differences and similarities of culture between the negotiators for sake of a successful intercultural negotiation. The representatives require not only to deal with the abilities of selecting the technical communication strategy, but also to acquire the cultural environments of the negotiation about both parties.

In order to help people distinguish the multiple cultural differences in the world, Hofstede summarized the core contents of the questionnaires from subsidiaries of IBM, thus identified a theory of several four cultural dimensions according to his earlier diligent and qualitative research in a systematic perspective(Tung, 2006). There are four dimensions for identifying the major cultural differences: individualism/ collectivism; power distance; uncertainty/avoidance, and masculinity/femininity. Dimension of individualism refers to relationship and distinction between the collective and the individual; dimension of power distance is about human inequality; dimension of uncertainty avoidance argues tolerability of ambiguity and uncertainty in a specific society; dimension of Masculinity focuses on the characteristics of men and women in different nations(Hofstede,2001).Hofstede proposed that business transaction, decision making and business negotiations were impacted by cultural differences, thus it is important to improve the sensibility of culture for international businessman (Chang, 2002). Later, Hofstede and Bond (1997) supplied another dimension to complete the earlier theories, this fifth cultural dimension was regarded as Confucian dynamism by them to differentiate Chinese cultural values from Western cultural values. Hofstede and Bond realized that cultural characteristics of a specific nation practically remain the same over time. For instance, Chinese culture has been dominated by the pragmatic and moral principles of Confucius since $500 \mathrm{BC}$, people's thoughts and actions, parental control and gender roles are all been guided by the rules of Confucius persistently. Although some Chinese people have migrated to Western countries in order to seek more development opportunities, Confucianism remains to influence their behaviors intensely.

\section{INDIVIDUALISM AND COLLECTIVISM}

The dimension of individualism and collectivism represents the manners people live together. Hofstede defines this dimension as follows: "for Collectivism, people are integrated into tight in-groups, they should commit themselves to pledging loyalty to the in-groups; while the ties of individuals are not close-knit, Everyone merely takes responsibility to him/herself and her/his family." (Hofstede, 2001, p.225). In collectivistic culture, people get along well with the group. Self-concept is not taken seriously in social interactions. They all desire to be approved by certain groups, comply with the group's norms and values and depend on the collective psychologically. People are responsible and loyal for the group, their interdependence is encouraged and promoted in order to approach social obligations. When the group needs people to sacrifice benefits, people will carry out instructions unhesitatingly. Collectivists pay more attention to reliable long term relationships for sake of securing the group overtime. There exist differences among people in collectivistic cultures concerning attitudes to members inside and outside of their group on the basis of these group identities. The group takes into account in major factors for setting goals. Collectivist cultures do not stress individual targets but emphasize interdependent activities for the group's benefits. Hence, it is not easy thing to get at the meaning of collectivist values for individuals from highly individualist cultures

On the contrary, individualism means that people pay attention to themselves achievements, the characteristics of the individual are self-identity, self-image, self-respect and self-esteem, and the individuals are regarded as the center and the most important parts of society. It is more important for the individual to enhance and realize the self-worth in the social setting, thus competitions between individuals appear frequently (Hofstede, 2001). People are influenced to be independent in individualistic cultures, individuality is promoted by norms and institutions, personal ambition are encouraged to come true. Individuals own options of signing agreements according to personal preference. The individual's interest surpasses the group's interest. In individualistic societies, there is not the whole concept of integrated system, people's judgment is based on their personal characteristics rather than the group's values and identities. People tend to define others by their accomplishments, different levels of wealth or living standard, etc. Individualistic cultures are more indifference and detached, goals are set just with minimal consideration.

Power distance means the extent of distribution about power, prestige, and wealth. The dimension of power distance emphasizes the degree of inequality among different people. Power distance is defined by Hofstede as "a measure of the interpersonal power or influence between boss and subordinate as perceived by the less power of the two" (2001, p.83)

In general, hierarchy in high power distance culture is regarded as the foundation for people to build and sustain relationships with others (Hofstede, 2001, p.107). In high power-distance cultures, social power is distributed according to a vertical social structure. People's statuses and functions from their perceptions in social interactions are largely unequal and complementary, and they accept reality of inequalities in aspects of prestige, law, politics, fortune and status, etc. Social status is closely bound up with social power. The authority figures invariably make decisions due 
to vertical interpersonal relationships. Also, parents expect children to be obedient. People who have higher status expect the respect from others. The countries in high power distance culture tend to be more authoritarian, thus reinforce the differences among people. The relationships between superiors and subordinates in the high power distance workplace are regarded as existentially unequal, there is a deep gap maximized by Power.

\section{CONCLUSION}

Low power distance cultures tend to apply a relative horizontal structure in terms of social relationships. People judge other people based on their deeds rather than their age, social roles and power. They adopt the tolerated attitudes to different opinions and behaviors. They try to be more informal and direct in social interactions. (Hofstede, 2001, p.107) Egalitarian cultures prevail and people share the decision-making authority of democracy. Application of power is quite limited except legitimate purposes. Subordinates and bosses have equal status in the low power distance workplace, democracy is a significant characteristic, bosses can consult their subordinates instead of making arbitrary decisions by themselves, and the ideal bosses are more accessible. Furthermore, Lower power distance is related to higher national wealth. By contrast, high power distance is associated with the large population.

\section{REFERENCES}

[1] Chang, L. C. (2002). Cross-cultural differences in styles of negotiation between $\mathrm{U}$.

[2] Davis, L. (2001). Doing culture: Cross-cultural communication in action. Beijing: Foreign Language Teaching and Research Press.

[3] Fang, T. (2005). Challenge and change in China's development: An enterprise perspective. London: Routledge Curzon.

[4] Hofstede, G. (2001). Culture's consequence. Beverly Hills, CA: Sage. 